\title{
MISCELÁNEA
}

\section{Sueños y literatura en “Cuentos de un Inconsciente” de Evaristo Montaño}

\section{Dreams and literature in "Tales of an Unconscious" by Evaristo Montaño \\ Sonhos e literatura em "Contas de um Inconsciente" de Evaristo Montaño}

Francisco Herrera-Rodríguez (Profesor jubilado. Historia de la Enfermería. Facultad de Enfermería y Fisioterapia. Universidad de Cádiz)

Cómo citar este artículo en edición digital: Herera-Rodríguez, F. (2018). Sueños y literatura en "Cuentos de un Inconsciente" de Evaristo Montaño. Cultura de los Cuidados (Edición digital), 22(51). Recuperado de <http://dx.doi.org/10.14198/cuid.2018.51.20>

Correspondencia: Santo Domingo de la Calzada, 11-3º A. 11012-Cádiz.

Correo electrónico: fraherod57@gmail.com

\section{CUENTOS DE UN INCONSCIENTE Evaristo Montaño}

Libros Canto y Cuento. Colección Nuevas Voces. Jerez de la Frontera, 2014. Tercera edición. 86 páginas.

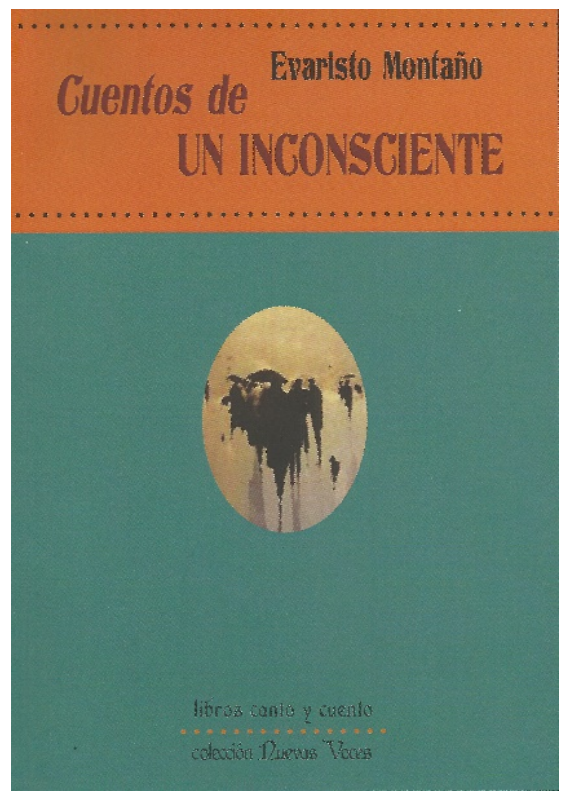

Figura 1: Portada de "Cuentos de un inconsciente”, de Evaristo Montaño (2014). 


\begin{abstract}
"Tales of an unconscious" is the first book by Evaristo Montaño; the author presents in this work a collection of stories or micro-stories with a marked oneiric accent, in which he contributes originality and literary quality, being his work influenced by Carl Gustav Jung and Gabriel García Márquez, among other authors.
\end{abstract}

Keywords: Evaristo Montaño, literature, micronarratives, stories, Carl Gustav Jung, Jerez de la Frontera.

\section{RESUMEN}

"Cuentos de un inconsciente" es el primer libro de Evaristo Montaño; el autor presenta en esta obra una colección de cuentos o microrrelatos de marcado acento onírico, en los que aporta originalidad y calidad literaria, influyendo en su obra Carl Gustav Jung y Gabriel García Márquez, entre otros autores.

Palabras clave: Evaristo Montaño, literatura, microrrelatos, cuentos, Carl Gustav Jung, Jerez de la Frontera.

\section{RESUMO}

"Contos de um inconsciente" é o primeiro livro de Evaristo Montaño; o autor apresenta neste trabalho uma coleção de histórias ou microhistórias com um acentuado sotaque onírico, no qual ele contribui originalidade e qualidade literária, influenciando sua Carl Gustav Jung e Gabriel García Márquez, entre outros autores. Palavras-chave: Evaristo Montaño, literatura, contos, histórias, Carl Gustav Jung, Jerez de la Frontera.

"De toda la memoria, sólo vale el don preclaro de evocar los sueños”. Antonio Machado.
El tren avanza y desde la ventanilla se ve la Sierra de San Cristóbal, poco después aparece El Portal y la antigua Azucarera con sus nidos de acomodadas cigüeñas, en un santiamén estamos en la estación de Jerez de la Frontera con sus republicanos azulejos. Hemos llegado a la ciudad de los presagios, aunque quizás esto se puede decir de cualquier ciudad a la que llegue un viajero con predisposición de encontrar El Aleph borgiano o algún hecho o signo que haga más entendible la vida, que ya es decir.

El viajero cuando llega a esta ciudad, sin prisas y sin quehaceres profesionales, mira a un lado y a otro, y dirige sus pasos a los lugares que le indica un daimón misterioso que sabe Dios si está por los suelos, por los cielos o dentro de su persona. Acompañado va siempre por las sombras alargadas de Manuel Torre, de Fernando Terremoto y por los naufragios de Cabeza de Vaca; camina por el Gallo Azul, por San Miguel, explora las callejas de la judería, se para a contemplar el cielo a través de los techos volados de las antiguas bodegas, Jerez se manifiesta entonces con dolor de saeta como un Sarajevo de expolio y catástrofe, aunque sigan sus calles y sus iglesias oliendo a soleras que custodian caldo eterno. Y por algún rincón ve correr a González Ragel que huye con su esqueletomaquia debajo del brazo antes de que lo ingresen en Ciempozuelos.

Otras veces el viajero se para delante del plateresco municipal, del gótico mudéjar de San Dionisio; busca La Virgen niña de Zurbarán o se adentra por calles sombreadas que conducen a una misteriosa bodega, con un patio enramado de pámpanos y racimos, que reúne en sus naves a Murillo, Velázquez, El Greco y a Goya. O busca la paz en El Retiro con su aliento de fresnos medicinales. Incluso alguna vez el viajero ha creído encontrar el misterioso Aleph en la casa de un anciano hospitalario, allá por Santiago, con paredes encaladas que todavía guardan un ayer de bulerías y jaleos pasados por el hambre y las fiestas compartidas de una boda, de un bautizo o de una buena cosecha. Otras veces en cambio saca de su bolsillo el libro del poeta de guardia, manual de infractores, que le ayuda a entender las injusticias de la vida y el por qué de esa arquitectura innoble que salpica aquí y allá las calles de la ciudad, aunque sin conseguir matar su belleza. 
En una de estas caminatas telúricas y sonámbulas, el viajero encaminó sus pasos por la cera sombreada de Porvenir hacia las Angustias, y sin pensarlo decidió meterse hacia San Miguel por Granados, con ganas de seguir por allí hacia la Plazuela; pero al entrar en esa calle cambió su intención al ver un escaparate con libros y un rótulo: “La luna vieja”, librería de lance. Dentro una estancia luminosa, cargada de libros de todas las materias. Compró algunos libros y vio uno encima del mostrador titulado "Cuentos de un inconsciente”; preguntó al librero y éste le dijo que él era el autor de esos cuentos dictados en sus sueños. Así fue como el viajero conoció a Evaristo Montaño, librero de lance al que le quedan pocos años para ser sexagenario, autor de este libro onírico de bellísima prosa en el que se impone esa otra realidad que alumbró Sigmund Freud; aunque todo esto de los sueños viene alentando la vida de los hombres desde que el mundo es mundo, antes incluso de esas incubatio celebradas en los templos de Grecia y Roma en nombre de Asclepio o Esculapio. Esos sueños de Quevedo, de Bécquer, de Proust, de Borges, de Cortázar, de Kafka. Esos sueños que pueblan la literatura universal y que permiten que nos comprendamos mejor a nosotros mismos y a los demás. Esos sueños que Evaristo Montaño cultiva sobre todo en los huertos de Carl Gustav Jung y de Gabriel García Márquez. El inconsciente colectivo y los ojos de perro azul. Sueños que permiten entender las cosas extrañas e imposibles que suceden en la vida. Cosas extrañas e imposibles que como dice Quevedo suelen suceder cuando "yo tal estaba, que di conmigo en el sueño y en el suelo obediente y cansado".

Para soñar todo lo soñado en estos cuentos de un inconsciente, Evaristo Montaño ha soñado varias vidas en esta vida: la de agente de seguros, entrenador deportivo y propietario de un gimnasio, ha hecho número en las colas de las oficinas del paro y ha recogido un diploma de técnico en energía termosolar que sin duda lo faculta como perito en lunas viejas; se ha soñado en la Escuela de Artes y Oficios pintando los azules de Joan Miró y las fabulaciones surrealistas de Dalí, y ahora sueña cada noche con escribir un segundo libro con sueños satíricos, de ese libro uno de sus heterónimos llamado Juan de las Viñas me ha enviado un relato inédito titulado "Autorretrato" del que reproduzco un fragmento con permiso de su soñador:

“...callado hasta que hablo, alérgico a la adelfa, al polvo de las cosas y las multitudes, posadolescente apenas madurado, artista de los buenos, de los pobres, deportista por deformación profesional, motero deseoso de alcanzar un Cabo Norte cada vez más lejano, fabricante y soñador de extrañas bicicletas, con una inocente doble vida, remero canicular curricandero, con el pellejo duro de los palos y por dentro sensible a la belleza, solitario imposible (...). Esto y algunas cosas más que dejo en la impresora, es lo que soy”.

En los sueños de Evaristo Montaño resucita del mundo de los muertos Perseveranda Peña; las princesas se despiertan con un beso pero remolonean y reivindican media horita más de almohada y edredón; se produce la kafkiana metamorfosis de un hombre en dibujo animado; se hacen sueños por encargo a los amigos pavimentando playas con losetas de gres; en el mercadillo de Oneirokritiká un hombre con bigotes dalinianos vende pescadillas de su propio huerto, recién recogidas del árbol; los dioses sueñan a los hombres y se acarician el loto que les crece en el ombligo. $\mathrm{Y}$ el vino de Rodas y el gárum de Gades convierten al soñador en Luciano.

Humor, surrealismo, erotismo y una prosa limpia con imágenes poéticas y metáforas que conmueven al lector y le hacen cobrar conciencia que está ante un escritor que viene de una estirpe literaria importante, a veces aparece el humor de las greguerías o "El doctor inverosímil” de Ramón Gómez de la Serna, y en otras ocasiones como en los cuentos "Doble vida” o “El alicante” asoma el perfume de Gabriel García Márquez y su deslumbrante y seductor realismo mágico. Evaristo Montaño le confiesa al viajero su devoción por un cuento del autor colombiano, “Ojos de perro azul”, y también que se siente más junguiano que freudiano. Ahí está el imponente ensayo de Sigmund Freud, "La interpretación de los sueños”, de finales del siglo XIX, en el cual el médico austriaco concibe el análisis de los sueños como una vía hacia el conocimiento de lo inconsciente; mientras que, como apunta Ursula Oberst, para Jung “el sueño es una expresión normal y creativa del inconsciente y no la reaparición parcial de contenidos reprimidos". La función de los sueños, según Jung, sería “la 
de restaurar el equilibrio psicológico del soñador”. Quizás en estas ideas del médico suizo, y en que los sueños pueden ser un "tesoro creativo”, podría estar el fundamento de las simpatías de Evaristo Montaño por Carl Gustav Jung.

El viajero sale de la librería de lance y deja al autor con sus libros, sus cuadros y sus próximos relatos satíricos; encamina sus pasos hacia la estación de tren y por un momento piensa si Evaristo Montaño y “La luna vieja” no serán un sueño. Luis Cernuda se debatía entre la realidad y el deseo, y como buen becqueriano, también entre los sueños. Sueños que cuando te tocan con sus dedos rosas en los ojos, como se preguntaba Bécquer, ¿...de la cárcel que habito huye el espíritu/en vuelo presuroso?”.

En estos "Cuentos de un inconsciente", sin duda, vuela presuroso el espíritu libre de Evaristo Montaño. Jerez ha sido una vez más para el viajero la ciudad de los presagios.

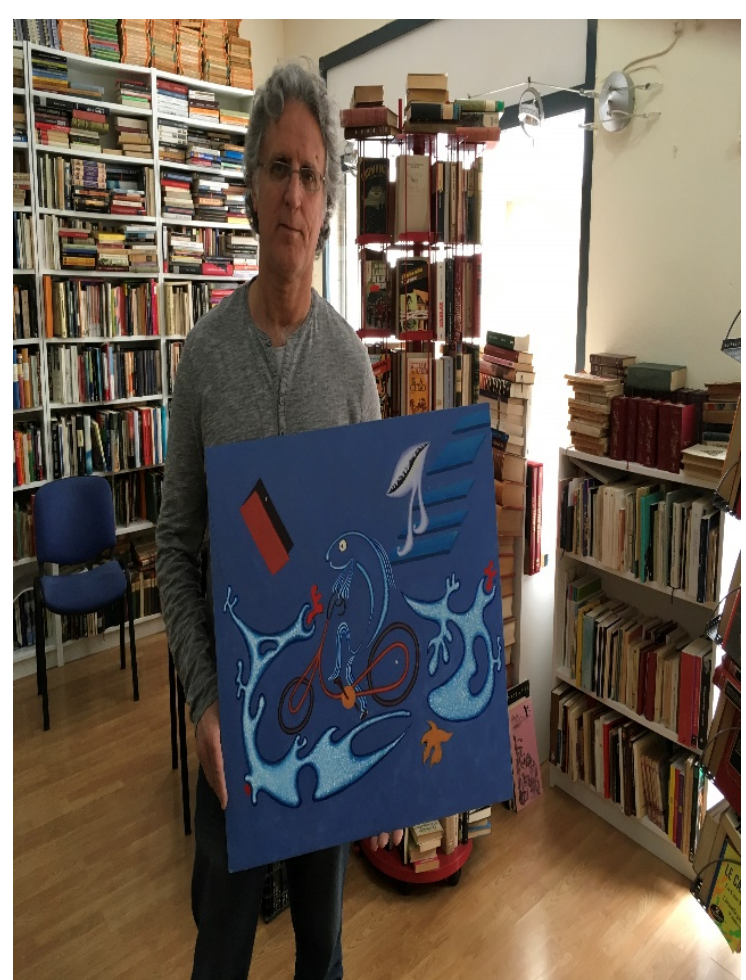

Figura 2: Evaristo Montaño en la librería de lance "La luna vieja” de Jerez de la Frontera, con su cuadro “El sueño de la sardina”. Fotografía: F. Herrera (Abril 2018). 